\title{
Experiences with making difficult decisions of the family caregivers of patients on prolonged mechanical ventilation: a qualitative study
}

\author{
Yi-Wei Lee ${ }^{1}$, Yu-Shan Hsieh ${ }^{2}$, Feng-Hang Chang ${ }^{3}$, Yi-Ling Wu ${ }^{4}$, Sheng-Jean Huang ${ }^{5,6}$, Yi-Han Lee ${ }^{5,7}$, \\ Yang-Ching Chen ${ }^{1,8,9,10}$
}

${ }^{1}$ Department of Family Medicine, Taipei Medical University Hospital, Taipei; ${ }^{2}$ Department of Basic Nursing Science, College of Nursing, Korea University, 145 Anamro, Seongbukgu, Seoul, 02841, Republic of Korea; ${ }^{3}$ Graduate Institute of Injury Prevention and Control, Taipei Medical University, Taipei; ${ }^{4}$ Academy of Humanity and Innovation, Taipei City Hospital, Taipei; ${ }^{5}$ Taipei City Hospital, Taipei; ${ }^{6}$ Surgical Department, Medical College, National Taiwan University, No. 1, Sec. 4, Roosevelt Rd., Taipei; ${ }^{7}$ Department of Family Medicine, Taipei City Hospital, Zhongxing Branch, Taipei; ${ }^{8}$ Department of Family Medicine, School of Medicine, College of Medicine, Taipei Medical University, Taipei; ${ }^{9}$ School of Nutrition and Health Sciences, College of Nutrition, Taipei Medical University, Taipei; ${ }^{10}$ Graduate Institute of Metabolism and Obesity Sciences, Taipei Medical University, Taipei

Contributions: (I) Conception and design: SJ Huang, YL Wu, YH Lee, YC Chen; (II) Administrative support: SJ Huang, YC Chen; (III) Provision of study materials or patients: YL Wu, YH Lee, YC Chen; (IV) Collection and assembly of data: YL Wu, YH Lee, YC Chen; (V) Data analysis and interpretation: YW Lee, YS Hsieh; (VI) Manuscript writing: All authors; (VII) Final approval of manuscript: All authors.

Correspondence to: Yang-Ching Chen, PhD, MD. No. 252, Wuxing St., Xinyi District, Department of Family Medicine, Taipei Medical University Hospital, Taipei Medical University, Taipei 11043. Email: melisa26@tmu.edu.tw.

Background: Family caregivers of patients on prolonged mechanical ventilation (PMV) may encounter challenges concerning medical decision-making besides witnessing patient suffering. Palliative care (PC) should be a good support for both patients and caregivers; however, for PMV families, PC is not always a choice through long companion time. This qualitative study clarifies family caregivers' burden of assisting patients on PMV and evaluates the need for PC information and support.

Methods: Interviews were caregivers of patients on ventilator support for more than 60 days in five hospitals of the Taipei City Hospital System. Based on phenomenology, this study was conducted by using a semi-structured questionnaire comprising three questions: (I) what was the most crucial moment of deciding to intubate? (II) how would you describe the quality of life of your ventilator-dependent family member? (III) what type of assistance do you expect from the PC team for your ventilator-dependent family member?

Results: Twenty-one caregivers of patients on PMV in five hospitals of the Taipei City Hospital System agreed to participate in face-to-face interviews. The identified themes, including stressful decision-making, companion pain/discomfort, and unwillingness to accept PC, elucidated the difficulties experienced by caregivers when providing care.

Conclusions: Understanding family caregivers' experiences can enable physicians to improve communication with them, encourage the PC team to support them during surrogate decision-making for patients on PMV during critical moments, and enhance the overall PC service.

Keywords: Prolonged mechanical ventilation (PMV); palliative care; respiratory care ward (RCW); caregiver burden

Submitted Dec 16, 2019. Accepted for publication Apr 07, 2020.

doi: 10.21037/apm-19-621

View this article at: http://dx.doi.org/10.21037/apm-19-621 


\section{Introduction}

Prolonged mechanical ventilation (PMV) increases the risk of complications during intensive care unit (ICU) and hospital stays $(1,2)$ in addition to increasing the death rate and costs (1). Notably, in Taiwan, patients with acute respiratory failure can stay in the ICU for up to 3 weeks. After 42 days, if ventilation is still required, patients are transferred to a respiratory care center or subacute unit. After 60 days, patients must be transferred to a respiratory care ward (RCW) (3). However, a practical mortality prediction model that provides quantitative guidance to clinicians, patients, and family caregivers regarding prognosis has not been established (4).

Most patients on PMV in long-term care units have a decreased consciousness level and are unable to make medical decisions, including those regarding palliative care (PC) and ventilator withdrawal. In 2000, the Taiwan Bureau of National Health Insurance (NHI) implemented the integrated prospective payment program for patients on PMV to reduce the demand for crowded and costly ICU $(5,6)$. Nonetheless, since 2000, the number of patients on PMV has increased (7.24 times higher by 2009) (7), the duration of mechanical ventilation usage and stay has increased, the weaning rate in patients on PMV has decreased from $68.1 \%$ to $64.2 \%$ (6), and the percentage of elderly patients ( $>65$ years) on PMV has increased to $88 \%$ in Taiwan (7). Most patients who receive PMV live only 1.5 years longer and $62 \%$ have impaired consciousness and poor quality of life (QOL) (8). Decision-making responsibility often lies with their families, who play the role of surrogate decision maker.

The role and responses of surrogate decision-makers have been studies (9); however, few studies have focused on the condition of patients on PMV. A quantitative study by Chen et al. (10). reported the personal experience of primary family caregivers of patients on PMV in Taiwan, starting from the point of decision to intubate to the present PMV condition. Nonetheless, the literature has some unresolved questions, such as why these family caregivers opted for PMV and what prevented them from access to PC during the chronic illness phase. PC is structured to support the decision-making dilemma because it is a type of patient care that prioritizes patients' will and relief from suffering (physical, spiritual, or psychological) $(11,12)$ and improves the quality of life of patients, their families and their caregivers, defined by WHO; in our study, we emphasized the aspect of relieving in case of pain and psychiatric support of caregivers. In reality, caregivers often reject PC (9), thus indicating a communication gap between physicians and caregivers. This study performed qualitative analysis to explore the circumstances faced by caregivers when choosing PMV for their patients and how PC can intervene at a critical moment during the PMV course. Our aim was to reveal the lengthy travails experienced by Taiwanese families during their family member's illness until they understand the palliative team's role in supporting patients on PMV. Through interpretation of the interviews, we hope to improve the approaches to providing support to caregivers and thereby help them cope with the stress of caring for chronically ill patients on PMV.

\section{Methods}

\section{Design and sample}

The study adopted a phenomenological approach and recruited 21 family caregivers of patients admitted to an RCW. They were recruited by the assistant, who explained the purpose of the research before obtaining informed consent, and complied with the principles outlined in the Helsinki Declaration. We requested for a detailed description of the caregivers' experiences to select appropriate participants for this study. The participants represented various categories of age, gender, and relationship to their patients.

First, we identified patients who fulfilled the following criteria: (I) over 18 years of age, (II) had received ventilator support for more than 60 days, and (III) were admitted to a long-term RCW at one of the five hospitals in the Taipei City Hospital System. Because patients on PMV are often limited in their expressions of will and thoughts, their family caregivers were recruited, and only one primary caregiver per patient was enrolled in the interview. All the surrogate decision-maker were all legally identified relatives according to Hospice and Palliative Care Regulation. Caregivers were required to complete a detailed questionnaire and participate in a personal interview to recall their experiences as well as the considerations made when opting to use PMV and its observed effects. Face-to-face interviews were conducted in 2016.

\section{Data collection}

Based on phenomenology, we created a semi-structured questionnaire to address the critical moments during 
1. What was the most crucial moment to the decision of intubation?

2. How would you describe the QOL of your ventilator-dependent family member?

3. What kind of assistance do you expect from the palliative care team assigned to your ventilator-dependent family member?

Figure 1 Open-ended questions in this qualitative study.

prolonged companionship with a patient on PMV, exploring the feelings and thoughts of the interviewee. We enlisted a panel of 12 experts to identify the question constructs. These experts reviewed the items in the questionnaire in terms of their appropriateness, need for revision, and need for removal.

Eventually, 21 eligible family caregivers of patients from the five hospitals of the Taipei City Hospital System who were willing to participate in a one-on-one interview were invited to enroll in the qualitative study.

Interviews were conducted by a trained research assistant who had previously been a social worker in a quiet, private room of the hospital outside the RCW where the family caregivers could be comfortable sharing their stories. At the beginning of each interview, a consent form was signed by the family caregiver. All interviews were audiorecorded. Each interview was composed of three openended questions, as shown in Figure 1. Each interview had a duration of 40 to 50 minutes.

Basic information such as the caregivers' age, gender, and relationship with the patient were collected in addition to the patients' PMV duration. A research assistant conducted all interviews and collected the data. The Institutional Review Board of Taipei City Hospital (TCHIRB: 10412121) approved the study protocol, which complied with the guidelines of the Declaration of Helsinki (as revised in 2013).

\section{Data analysis}

An initial list of codes for the analysis of interviews was established by two investigators (Y. W. Lee and Y. C. Chen), who independently reviewed the recorded interviews for themes and determined the final list of codes. Subsequently, Y. W. Lee coded all transcripts and categorized them according to their themes. Finally, the investigators discussed the results until they reached a consensus and then summarized the codes of sentences.

\section{Results}

Overall, 21 family caregivers - surrogate decision-makersof patients on PMV agreed to participate in in-depth faceto-face interviews. Their basic information is presented in Table 1. Of the caregivers, their mean age was 60 years and $17(80.9 \%)$ were the children of patients. The mean ventilation duration of patients was 23.4 months. Table 2 present the comorbidity of the patients. Table 3 was for the timing of the family conferences.

Finally, we coded the phrases into three themes, revealing the processes that the caregivers had undergone while accompanying patients from intubation to PMV, as shown in Figure 2. Each theme is illustrated thoroughly in the paragraphs that follow.

\section{Stressful decision-making}

\section{Initiation phase}

This theme was encountered in situations where in which the patient was in a critical condition and the family caregiver had to make decisions. These critical conditions included the patient collapsing, sudden desaturation (dyspnea), or an overall deteriorated condition-all of which can confuse and shock families.

"In the emergency department, be suddenly had difficulty breathing. There was a doctor from the intensive unit... I had never been in such a situation, witnessing a tracheostomy... so I didn't know... It just happened in the ER, so suddenly... hard to breathe..." (Participant 2, son, caregiver for 48 months).

\section{Feeling of time stress}

Some caregivers mentioned that it was stressful during emergencies to understand the patient's clinical situation because of an insufficient amount of time. The shock of seeing their family member in a critical state and the limited time for decision-making was stressful. This is particularly evident in the following account:

"When his condition became critical, bis blood pressure and pulse dropped immediately... but before that moment, there was no one to inform us or talk to us. When you face a medical emergency, of course you choose intubation." (Participant 3, son, caregiver for 72 months).

Most patients, as described by the caregiver, either lost consciousness or were unable to convey their will. One 
Table 1 Characteristics of main family caregivers of patients receiving prolonged mechanical ventilation (PMV)

\begin{tabular}{|c|c|c|c|c|}
\hline No. & Gender & Age & Duration (months) & Relation \\
\hline 2 & Male & 50 & 48 & Son \\
\hline 3 & Male & 68 & 72 & Son \\
\hline 4 & Male & 65 & 12 & Son \\
\hline 6 & Female & 51 & 6 & Daughter \\
\hline 7 & Male & 52 & 12 & Son \\
\hline 8 & Female & 48 & 36 & Daughter \\
\hline 9 & Female & 51 & 16 & Wife \\
\hline 12 & Male & 38 & 72 & Son \\
\hline 13 & Male & 50 & 22 & Son \\
\hline 14 & Female & 37 & 16 & Daughter \\
\hline 15 & Male & 59 & 16 & Son \\
\hline 16 & Female & 60 & 2 & Daughter \\
\hline 17 & Female & 49 & 2 & Daughter \\
\hline 18 & Female & 62 & 60 & Daughter \\
\hline 19 & Male & 53 & 12 & Son \\
\hline
\end{tabular}

of the family members had to take over suddenly as a surrogate decision-maker. The decision of whether to select mechanical ventilation is often based on the decision of whether to try to save the patient's life or allow the patient to pass on. However, family caregivers experience emotional turmoil when confronted with the imminent death of a loved one.

"Suddenly, he asked if I chose intubation or not, to save him or not... in that case, you surely choose intubation, of course you should save him." (Participant 3, son, caregiver for 72 months).

\section{Suffering companion}

\section{Prolonged phase}

Patients should be converted to a tracheostomy if they are not expected to wean off the ventilator within 2 or 3 weeks after intubation. The majority of family caregivers described a poor QOL of patients on mechanical ventilation. Patients are unconscious, rely on a nasogastric tube, and have difficulty communicating.

\section{Feeling of frustration}

At the time of intubation, some caregivers do not realize that intubation and ventilation only partially help patients with their bodily functions and that the intubation is eventually switched to a tracheostomy. They expect the patient to recover smoothly from the disease. Most often, the prognosis is not well explained by physicians. Therefore, with limited information concerning the condition, family caregivers begin to question their decision to intubate the patient and wonder if the inability to think or move has rendered the patient's life incomplete. Furthermore, having to witness the patient living in an impaired state 
Table 2 Comorbidity of patients receiving prolonged mechanical ventilation

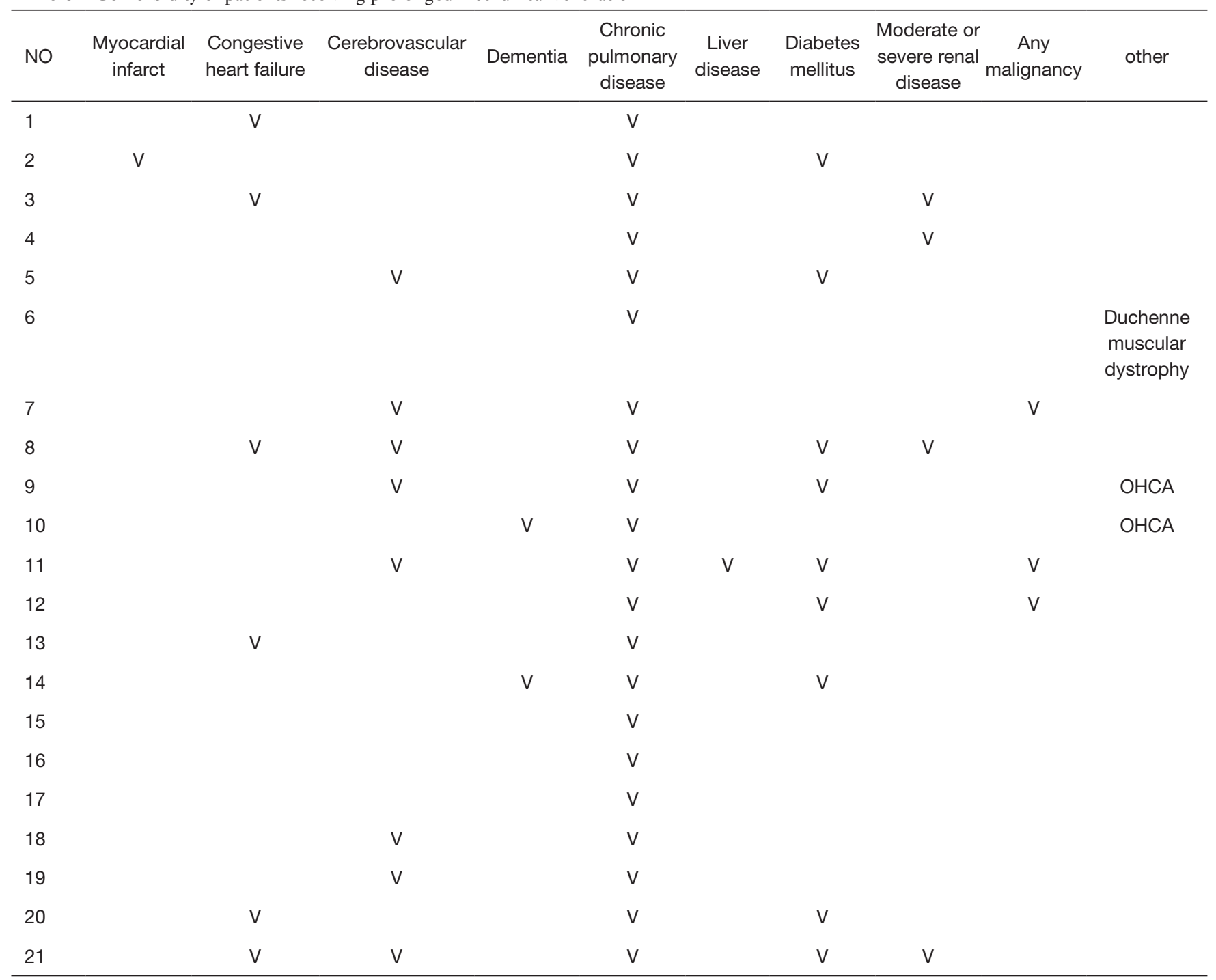

OHCA, out-of-hospital cardiac arrest; $\mathrm{V}$, diagnosed as the indicated disease.

can frustrate the caregiver, leading them to describe the condition as a tragedy.

"We didn't know be needed to be intubated for so long..." (Participant 4, son, caregiver for 12 months).

"At that moment, the doctor encouraged us to do the tracheostomy; I didn't know this decision would prolong not only bis life but also his suffering." (Participant 19, son, caregiver for 12 months).

\section{Unwillingness to accept palliative care}

\section{Chronic illness phase}

After being on mechanical ventilation for 60 days, patients often receive a tracheostomy and are transferred from the ICU to RCW. Most of these patients are unconscious and rely on others' care.

\section{Rejection of palliative care}

When we asked the surrogate decision-makers (caregivers) the question concerning $\mathrm{PC}$, their response generally became uneasy and passive. They refused to discuss the service of $\mathrm{PC}$ by rejecting the inclusion of $\mathrm{PC}$, expressing doubt regarding the efficacy of $\mathrm{PC}$, and rejecting the need for PC.

"I don't think he meets the criteria for palliative care. So... I don't knoww." (Participant 2, son, caregiver for 3 months). 
Table 3 Palliative family conference record

\begin{tabular}{|c|c|c|}
\hline No. & $\begin{array}{l}\text { Palliative family } \\
\text { conference }\end{array}$ & $\begin{array}{c}\text { Before/after admission } \\
\text { of RCW }\end{array}$ \\
\hline 1 & Yes & After \\
\hline 2 & Yes & After \\
\hline 3 & Yes & After \\
\hline 4 & Yes & After \\
\hline 5 & Yes & After \\
\hline 6 & Yes & Before \\
\hline 7 & Yes & After \\
\hline 8 & No & Nil \\
\hline 9 & Yes & After \\
\hline 10 & Yes & After \\
\hline 11 & Yes & After \\
\hline 12 & Yes & After \\
\hline 13 & Yes & After \\
\hline 14 & Yes & After \\
\hline 15 & Yes & After \\
\hline 16 & Yes & After \\
\hline 17 & Yes & After \\
\hline 18 & Yes & After \\
\hline 19 & Yes & After \\
\hline 20 & Yes & After \\
\hline 21 & Yes & After \\
\hline
\end{tabular}

$\mathrm{RCW}$, respiratory care ward.

"What can the palliative care team do for an unconscious patient?" (Participant 5).

"For now, we may not need them [palliative care team]. I will talk to my family someday." (Participant 20, wife, caregiver for 6 months).

\section{Discussion}

This study presents the difficulties faced by family caregivers during the clinical course of caring for patients on PMV. Most of our interviewees were children of patients and had a mean age beyond middle age (60 years old), indicating that the average age of patients was roughly 80 years. After the IPP program was implemented in Taiwan, there was a decrease in the weaning rate of mechanical ventilation among patients on PMV, and the length of hospital stay increased (6). In our study, the average mechanical ventilation time was 23.4 months, ranging from 3 months to 6 years. We defined PMV as the duration over 60 days, which is longer than the durations specified by other papers (13).

Through our interviews, we found that during PMV, the caregivers had to be the surrogate decision-makers during several critical moments. Notably, they typically selected the option that would save the patient's life. It would be difficult to evaluate the wishes of the patients with PMV themselves and advance directives regulation was not mature in Taiwan in 2016. In our study, there was only one patient's (No. 8) will was presented by their family. After the delegated decision had been made, the patient's condition remained stable for a certain amount of time, relying on ventilation and other parameters. However, when the patient could not wean off the ventilation, the patient required a tracheostomy. Caregivers experienced frustrated at witnessing the patient's poor QOL and suffering through medical interventions. Regardless of the complexity of the patients' comorbidity (Table 2), almost every family in our study expected positive outcomes or better QOL. Yet, there was no good prognosis predictor for PMV (14), and physician should still tell the family about the general medical concern to the family. The gap between physician and family was shown. Studies have indicated the significance of adequate communication between physicians and family caregivers for facilitating decision-making $(15,16)$. However, we discovered that the family caregiver became a surrogate decision-maker under emergency circumstances, and the decision made was based on whether to save the life of the patient; thus, caregivers often relied on the physician. In some cases, the doctors did not mention the prognosis even after the patients' conditions became stable. Studies have revealed that decision-making in this context is a complex process involving the wishes previously stated by the patient, religious beliefs, family dynamics, and possibly other factors $(17,18)$. According to the literature, physicians should also offer more options and additional information to families (18).

Decision to transfer patients to RCW was an important point, and most our patients' family didn't receive a family conference consultation before admitting according to Table 3. By the time of transfer to the RCW, patients had already been on mechanical ventilation for over 60 days, caregivers' hopes were fading, and their attitude had become passive and evasive because despite making 


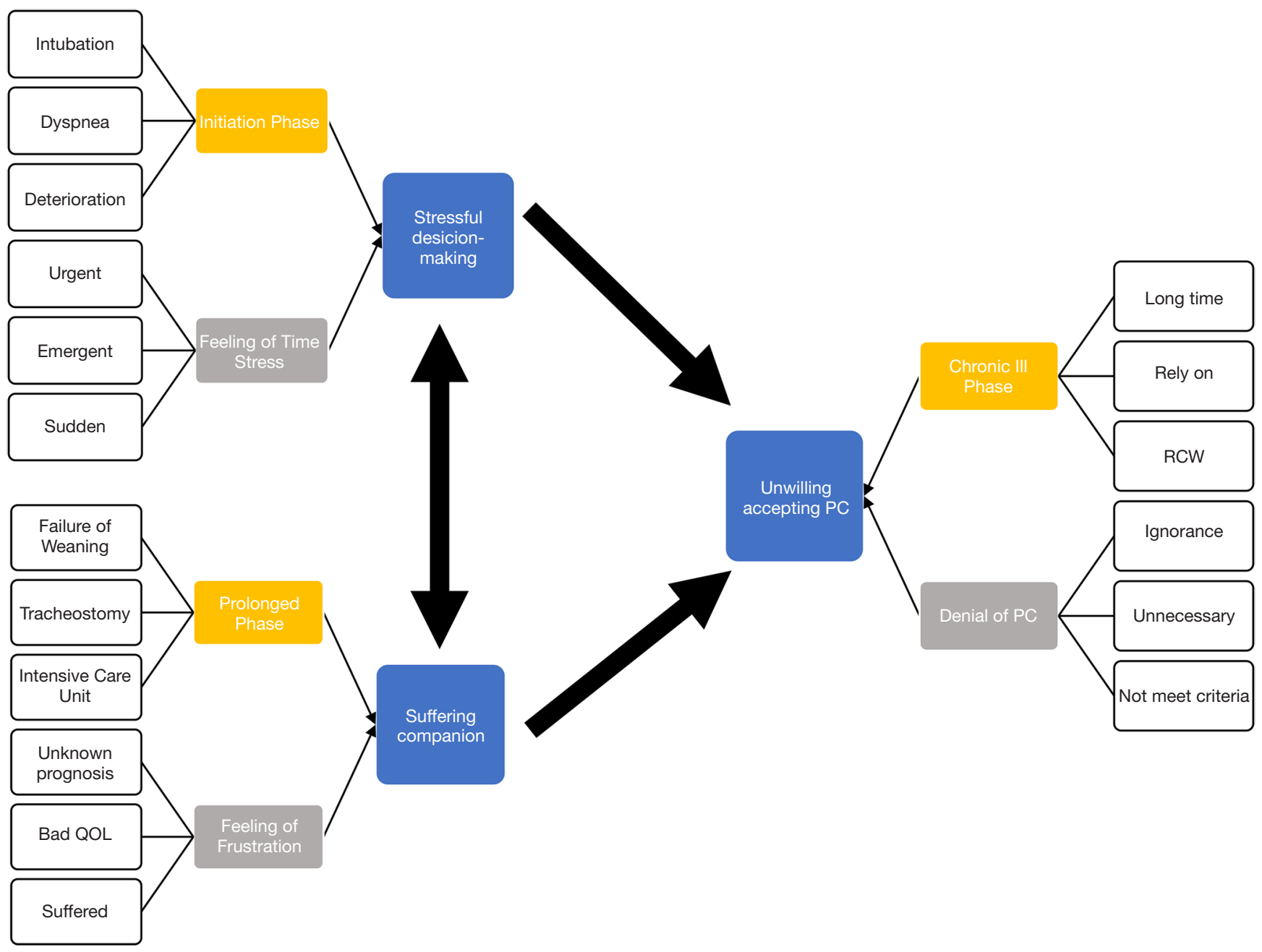

Figure 2 Themes identified.

several decisions for patients and witnessing various critical moments, the patients had not recovered. When faced with their family member's critical illness, families often experience anxiety and depression (19). With the inability to express themselves, patients are more likely to receive more aggressive life-sustaining treatments than they had stated during their end-of-life care discussions (20). Anxiety, poor patient QOL, and lack of awareness regarding clinical prognosis render caregivers helpless in making surrogate decisions for patients. During interviews, family members verbally expressed considerable hopelessness concerning prolonged patient suffering. Notably, the PC team may be an excellent support system for them. One study reported that poor QOL in patients and family caregivers' enhanced knowledge regarding $\mathrm{PC}$, increased the willingness to receive $\mathrm{PC}$, and withdraw from life-sustaining treatments in the terminal stage of life (10). However, the best time for the initiation of PC in PMV was still hard to define. According to our law, palliative care should be performed in a terminal illness. However, NHI has restricted the payment for malignancy and eight categories of severe diseases. It is difficult for physicians to categorize patients with PMV as end of life situation, as the result, palliative care was not directly provided. Nonetheless, the idea of integrating PC into emergency department practice at an early stage of malignancy has been proposed (21-23).

In our study, more issues have been disclosed. First, when we brought up the topic of PC, the interviewees seemed to avoid this word because they may have already faced several ordeals during PMV, which often reaches a duration of 
2 years. Second, PC was highly misunderstood, as exemplified by the question "What can the palliative care team do for an unconscious patient?" (Participant 11). The avoidance of attitude and ignorance made communication even harder to start.

We could not initially distinguish whether this misunderstanding was a form of denial or ignorance of PC. After reviewing the contexts and interviews, we noticed that the family caregivers demonstrated a similar attitudeavoiding the word PC. This attitude was mainly to avoid the topic of "death," commonly associated with PC, which prevented the caregivers from understanding PC or the services associated with it. We thought that this general attitude could become a problem for the family caregivers who genuinely need PC for patients on PMV.

In most countries, PC is increasingly being used among patients who are on PMV in ICUs (24). With the increasing demand for PC services, numerous physicians will undoubtedly face a situation wherein they may require the communication skills of the PC team at critical moments. However, this requirement can be challenging because of prognostic uncertainty, fear of causing distress, and the feeling of being unprepared for these conversations (25). In our study, numerous caregivers were still unaware of the various services offered by the PC team, and family conferences were mostly held late, which showed the passive attitude of physicians. Despite several studies proposing techniques to enhance the quality of communication $(26,27)$, few have demonstrated the effects of communication-focused interventions, such as palliative communication, on patients' and caregivers' experiences and outcomes (28). In addition to adopting an empathetic approach, a communication-focused intervention was observed to be better compliant with patients' wishes (29).

Accordingly, PC should be improved and provided to the families or caregivers of patients on PMV and should include discussion of prognosis, empathy for caregivers' emotions, and communication regarding the function of PC. Shared decision-making should be continually provided for patients not only at the initiation of intubation but also during the prolonged phase, which would help offload caregivers' stress.

The current study had several potential limitations worth mentioning. First, it was conducted in a single hospital system in Taipei. Presumably, our findings may not be representative of other regions of Taiwan or the world. However, the study was conducted in five different hospitals across Taipei city, and the trends for PMV in this health care system are similar to the national trends in Taiwan. Because the number of cases of PMV is increasing in other countries and regions, it is crucial to validate our findings in other areas. Second, our study was limited by difficulties in obtaining information about the patients' perspectives due to poor consciousness level of the patients as well as the cultural norms in Taiwan, most of the decisions were made by the families instead. Moreover, interviewees differed in their ability to express their emotions, thus, the information may not completely enough to reflect the whole story that they experienced. Third, we only coded in three themes separately from the interviews owing to the weak connection between three questions.

In addition, physicians can ease some of the frustration and anxiety of caregivers by providing them with more information regarding the patient's disease condition. Notably, less emotional burden and more advanced care planning are more likely to help the caregivers accept help from the PC team.

The decision to prolong the life of patients with emergency conditions or critical illnesses by using mechanical ventilation is never easy to make. Our study indicates that the family caregivers of patients on PMV often feel helpless and stressed owing to constant decision-making during critical moments and witnessing the suffering of their family members hinders them from seeking suitable help such as support from PC. By acknowledging the challenges faced by caregivers, physicians can improve crucial communication with them, provide support concerning surrogate decision-making for patients on PMV during critical moments, and enhance the overall service provided by the PC team.

\section{Acknowledgments}

We thank the multidisciplinary team, including chest specialists, respiratory therapists, and head nurses in each hospital of the Taipei City Hospital System. We also thank the researchers in the Department of Education and Research of Taipei City Hospital who assisted in the study design and questionnaire development.

Funding: None.

\section{Footnote}

Conflicts of Interest: All authors have completed the ICMJE uniform disclosure form (available at http://dx.doi. org/10.21037/apm-19-621). The authors have no conflicts 
of interest to declare.

Ethical Statement: The authors are accountable for all aspects of the work in ensuring that questions related to the accuracy or integrity of any part of the work are appropriately investigated and resolved. The study was conducted in accordance with the Declaration of Helsinki (as revised in 2013). The study protocol was approved by the Institutional Review Board at Taipei City Hospital (TCHIRB: 10412121). Written informed consent for participation was obtained from each participant.

Open Access Statement: This is an Open Access article distributed in accordance with the Creative Commons Attribution-NonCommercial-NoDerivs 4.0 International License (CC BY-NC-ND 4.0), which permits the noncommercial replication and distribution of the article with the strict proviso that no changes or edits are made and the original work is properly cited (including links to both the formal publication through the relevant DOI and the license). See: https://creativecommons.org/licenses/by-nc-nd/4.0/.

\section{References}

1. Loss SH, de Oliveira RP, Maccari JG, et al. The reality of patients requiring prolonged mechanical ventilation: a multicenter study. Rev Bras Ter Intensiva 2015;27:26-35.

2. Vora CS, Karnik ND, Gupta V, et al. Clinical profile of patients requiring prolonged mechanical ventilation and their outcome in a tertiary care medical ICU. J Assoc Physicians India 2015;63:14-9.

3. Lin MS, Yan YH, Wang JD, et al. Improved survival for an integrated system of reduced intensive respiratory care for patients requiring prolonged mechanical ventilation. Respir Care 2013;58:517-24.

4. Carson SS. Outcomes of prolonged mechanical ventilation. Curr Opin Crit Care 2006;12:405-11.

5. Cheng SH, Jan IS, Liu PC. The soaring mechanic ventilator utilization under a universal health insurance in Taiwan. Health Policy. 2008;86:288-94.

6. Liu CJ, Chu CC, Chen W, et al. Impact of Taiwan's integrated prospective payment program on prolonged mechanical ventilation: a 6-year nationwide study. Respir Care 2013;58:676-82.

7. Huang HH. Available online: General report of the national health insurance; National Health Insurance Administration 2012; http://www. cy.gov.tw/ sp.asp?xdUrl=./CyBsBox/CyBsR1. asp\&mp $=1 \& c t N o d e=910$

8. Hung MC, Lu HM, Chen L, et al. Life expectancies and incidence rates of patients under prolonged mechanical ventilation: a population-based study during 1998 to 2007 in Taiwan. Crit Care 2011;15:R107.

9. Nelson JE, Hanson LC, Keller KL, et al. The voice of surrogate decision-makers. family responses to prognostic information in chronic critical illness. Am J Respir Crit Care Med 2017;196:864-72.

10. Chen YC, Fan HY, Curtis JR, et al. Determinants of receiving palliative care and ventilator withdrawal among patients with prolonged mechanical ventilation. Crit Care Med 2017;45:1625-34.

11. Quest TE, Marco CA, Derse AR. Hospice and palliative medicine: new subspecialty, new opportunities. Ann Emerg Med 2009;54:94-102.

12. Lamba S, Mosenthal AC. Hospice and palliative medicine: a novel subspecialty of emergency medicine. J Emerg Med 2012;43:849-53.

13. Rose L, McGinlay M, Amin R, et al. Variation in definition of prolonged mechanical ventilation. Respir Care 2017;62:1324-32.

14. Ghauri SK, Javaeed A, Mustafa KJ, et al. Predictors of prolonged mechanical ventilation in patients admitted to intensive care units: A systematic review. Int J Health Sci (Qassim) 2019;13:31-8.

15. Azoulay E, Timsit JF, Sprung CL, et al. Prevalence and factors of intensive care unit conflicts: the conflicus study. Am J Respir Crit Care Med 2009;180:853-60.

16. Delva D, Vanoost S, Bijttebier P, et al. Needs and feelings of anxiety of relatives of patients hospitalized in intensive care units: implications for social work. Soc Work Health Care 2002x;35:21-40.

17. Cook D, Rocker G, Marshall J, et al. Withdrawal of mechanical ventilation in anticipation of death in the intensive care unit. N Engl J Med 2003;349:1123-32.

18. Ankrom M, Zelesnick L, Barofsky I, et al. Elective discontinuation of life-sustaining mechanical ventilation on a chronic ventilator unit. J Am Geriatr Soc 2001;49:1549-54.

19. Pochard F, Azoulay E, Chevret S, et al. Symptoms of anxiety and depression in family members of intensive care unit patients: ethical hypothesis regarding decision-making capacity. Crit Care Med 2001;29:1893-7.

20. Zaros MC, Curtis JR, Silveira MJ, et al. Opportunity lost: end-of-life discussions in cancer patients who die in the hospital. J Hosp Med 2013;8:334-40.

21. Meier DE. Increased access to palliative care and hospice services: opportunities to improve value in health care. 
Milbank Q 2011;89:343-80.

22. Meier DE, Beresford L. Fast response is key to partnering with the emergency department. J Palliat Med 2007;10:641-5.

23. Nelson JE, Hope AA. Integration of palliative care in chronic critical illness management. Respir Care 2012;57:1004-12.

24. Chatterjee K, Goyal A, Kakkera K, et al. National trends (2009-2013) for palliative care utilization for patients receiving prolonged mechanical ventilation. Crit Care Med 2018;46:1230-7.

25. Brighton LJ, Bristowe K. Communication in palliative care: talking about the end of life, before the end of life. Postgrad Med J 2016;92:466-70.

Cite this article as: Lee YW, Hsieh YS, Chang FH, Wu YL, Huang SJ, Lee YH, Chen YC. Experiences with making difficult decisions of the family caregivers of patients on prolonged mechanical ventilation: a qualitative study. Ann Palliat Med 2020;9(4):1742-1751. doi: 10.21037/apm-19-621
26. Liénard A, Merckaert I, Libert Y, et al. Transfer of communication skills to the workplace during clinical rounds: impact of a program for residents. PLoS One 2010;5:e12426.

27. Tulsky JA, Arnold RM, Alexander SC, et al. Enhancing communication between oncologists and patients with a computer-based training program: a randomized trial. Ann Intern Med 2011;155:593-601.

28. Houben CHM, Spruit MA, Groenen MTJ, et al. Efficacy of advance care planning: a systematic review and metaanalysis. J Am Med Dir Assoc 2014;15:477-89.

29. Brinkman-Stoppelenburg A, Rietjens JA, van der Heide A. The effects of advance care planning on end-of-life care: a systematic review. Palliat Med 2014;28:1000-25. 